\title{
Fresh insights into the palaeoecological and palaeoclimatological value of Quaternary non-pollen palynomorphs
}

\author{
Jean Nicolas Haas
}

Received: 16 October 2010/ Accepted: 19 October 2010/Published online: 4 November 2010

(C) Springer-Verlag 2010

The present volume 19 issue 5-6 comprises twelve contributions from 38 authors on microscopic non-pollen palynomorphs from Europe (England, France, Ireland, Italy), from Georgia, from the Black Sea corridor, from the Tibetan plateau, from Greenland, as well as from Ontario, Canada. These publications are presented in alphabetical order of contributing first authors. Most of the papers are related to oral and poster presentations which were given at the 2nd International Workshop on Non-Pollen-Palynomorphs (Extrafossils) at Innsbruck, Austria (August 28-30, 2006), organized by Jean Nicolas Haas, and at Symposium 25 Non-pollen palynomorphs, a key for disentangling climatic and anthropogenic pressure on Quaternary ecosystems, at the 12th International Palynological Conference and 8th International Organisation for Palaeobotany Conference, Bonn, Germany (August 31, 2008), organized by Jean Nicolas Haas, Didier Galop and Bas van Geel.

During the last two decades, non-pollen palynomorphs (NPPs) have received increased attention from Quaternary palynologists due to their ubiquity in all kinds of habitats and their abundance in different geological and extant sediment types, where they sometimes exceed, for example, the total number of pollen and fern spores.
Plant remains such as algal propagation cells and cysts, fungal spores and hyphae from plant parasites or coprophilous fungi and plant trichomes, and animal remains such as parasite ova, foraminifer linings and Neorhabdocoela eggs, together with textile fibres among others, therefore greatly add to our understanding of the evolution of past ecosystems worldwide. Non-pollen palynomorph findings may also help in disentangling plant and animal diversity changes due to climatic change and human impact.

In addition, most fungal and algal taxa as well as cyanobacteria have a much longer geological history than flowering plants. Non-pollen palynomorph studies as presented in this special issue of Vegetation History and Archaeobotany are therefore also highly relevant for palynologists and palaeoecologists specialising in the analysis of pre-Quaternary deposits.

Today, and even if the value of non-pollen palynomorphs is beyond any doubt, these microscopic objects are still often overlooked in research studies on past ecosystems, human impact and climate. As shown in this special issue, non-pollen palynomorphs greatly deserve our attention in future palaeoecological and palaeoclimatological research.

Communicated by F. Bittmann.

J. N. Haas $(\bowtie)$

Institute of Botany, University of Innsbruck,

Sternwartestrasse 15, 6020 Innsbruck, Austria

e-mail: Jean-Nicolas.Haas@uibk.ac.at 